\title{
An Evaluation of the Industrial Symbiosis Systems Modeling
}

\author{
Gisele Bortolaz GUEDES ${ }^{1}$, Victor Miranda de SOUZA and Milton BORSATO \\ Federal University of Technology - Paraná, Brazil
}

\begin{abstract}
Industrial symbiosis, a concept derived from industrial ecology, emphasizes the collaborative and synergic production among industries. The particular focus is on cyclical flows of resources (material, energy, water, and/or by-products), in order to minimize impacts on the environment. In this way, an industry could reuse the discarded resources of another industry as an input to production. Essentially, the characteristics of the interaction between components of the system define industrial symbiosis as complex and dynamic. Uncertainty, unpredictability, emergency, and adaptability are determining features of this interaction. The development of such an innovative system requires great effort. An important step is to create a representative model of this new reality to support system change. Hence, the present article develops an evaluation of the industrial symbiosis systems modeling. For this purpose, the research adopted a bibliometric and systemic analysis. The results presented in this paper are: (i) an analysis of scientific knowledge about the theme, (ii) the main points discussed and opportunities extracted in the literature, and (iii) the paradigms of industrial symbiosis modeling and simulating. In addition, this work will cooperate as a research base for the development of a new model, which intends to support decision-making processes, during the creation of symbiosis links.
\end{abstract}

Keywords. Systems Modeling, Simulation, Industrial Ecosystem, Industrial Ecology, Industrial Symbiosis.

\section{Introduction}

The development of new alternatives that ensure the inclusion of sustainability in industrial systems is a necessary strategy to promote economic, environmental and social well-being. There are several tools and approaches to support the integration of sustainability concepts into manufacturing practices [1]. The industrial ecology (IE) approach is a theory and practice that presents a way for the industrial system to achieve sustainable development goals [2].

The main IE objective is the closed circulation of industrial system resources with zero impact to the environment [3]. The IE aggregates tools and strategies to enable forms of joint use of natural resources, waste recycling, and reuse of inputs. The establishment of these networks allows an economy of natural resources combined with better use of inputs and industrial waste [4]. Hence, one of the IE fundamental properties is the system components integration to reduce: (a) resources inputs; (b) generation of pollutants; and, (c) waste outputs [1].

\footnotetext{
${ }^{1}$ Corresponding Author, Email: giselebguedes@gmail.com.
} 
Industrial symbiosis (IS) is an approach derived from IE [5]. The creation of synergies within a territory leads to the development of IS [6]. The symbiotic relationship between two or more industries aims to improve the physical exchanges of materials, energy, water, and by-products [7]. The key is to close the materials cycles, using waste from one facility as an alternative input to another facility [8, 9].

The IS network is considered a complex adaptive system according to characteristics as uncertainty, emergence, or adaptability, amongst others [10]. Modeling and simulating an industrial ecosystem based on IS strategy is a challenge. The structure of this complex system is sophisticated and contains a large number of components and process interacting frequently [11]. The IS strategy success is highly dependent on establishing a synergy among several spheres including physical, social and organizational ones [12]. An important topic to be explored is the IS evolution and dynamic process. In this way, modeling and simulation innovative methods could increase insight and understanding of the intrinsic complexity related to industrial sustainability transformative strategies [13].

Thereby, this paper aims to identify the current state and opportunities for modeling industrial ecosystems. For this purpose, the present article carries out a bibliometric and systemic analysis. As a result, this research consolidates the information about the theme, map the evolution of scientific knowledge, and thus, present the main points discussed in the literature. Moreover, this paper briefly discusses the main paradigms to industrial symbiosis modeling and simulating.

This research is original for conducting a joint evaluation of systems modeling and industrial ecology to support the development of industrial symbiosis environments. Besides, the study is relevant to cooperate with the research evolution as the subject field is relatively new.

The paper is structured as follows: the introduction is presented in this section, and the section 1 involves the methodological aspects of this research. In section 2, the analysis of scientific knowledge is presented, which include bibliographic portfolio selection stage, and bibliometric and systemic analysis. In this section 3, this article exposes the paradigms to model and simulate complex systems. The main conclusions, as well as a future research plan, are outlined in section 4 .

\section{Methodological Aspects}

Knowledge Development Process - Constructivist (ProKnow-C) was the methodological procedure adopted for the theoretical reference selection and analysis. The Laboratory of Multicriteria Methodology in Decision Support (LabMCDA) of the Federal University of Santa Catarina developed this procedure [14, 15]. ProKnow-C has transparency and integrated analysis criteria which provides a holistic view. [16]. The stages performed in this research were: i) bibliographic portfolio (BP) selection, ii) $\mathrm{BP}$ bibliometric analysis, and iii) BP systemic analysis.

The bibliographic portfolio is a set of publications with scientific recognition, which are aligned with the research theme. The bibliometric is a statistical analysis of the portfolio, while the systemic is content analysis. Furthermore, the systemic analysis is used to explore a given research subject according to the criteria determined by the researcher [17].

After this stages, the question of research and the general and specific objectives can be defined [18]. This article intends to describe the current state and the research 
opportunities related to systems modeling and industrial symbiosis studies. The software Endnote X7, a bibliography manager, and Microsoft Excel for data tabulation were used as a tool to support this structured literature review.

\section{Analysis of the Scientific Knowledge}

\subsection{Bibliographic Portfolio Selection Stage}

The bibliographic portfolio selection stage consists of three main steps: (a) selecting article sample, (b) filtering article sample and (c) testing BP representativity [14]. The aim is to create a bibliographic portfolio, which is a set of publications with scientific recognition aligned with the research theme.

The research axes, keywords and databases were defined. The two main research axes determined were: (i) systems modeling and (ii) industrial ecology. The keywords were derived from these research axes. The first keywords defined were: system modeling, agent based, system dynamics, discrete event, and simulation. The keywords defined for the second axes were: industrial ecology, industrial symbiosis, and industrial ecosystem. The boolean operators "and" and "or" were used to perform the combination of the two research axes. Moreover, databases used were: Web of Science, Scopus, Engineering Village, Springer, Science Direct, Wiley, Emerald, Proquest and IEEE. Only the scientific papers published in the last 5 years were considered in this research (between 2014 and 2019). In order not to depreciate the importance of emerging ideas, abstracts of new articles, published between 2017 and 2019, were thoroughly read.

After filtering article sample and testing representativity, the results achieved can be seen in figure 1 . In summary, 28 publications comprise the bibliographic portfolio.

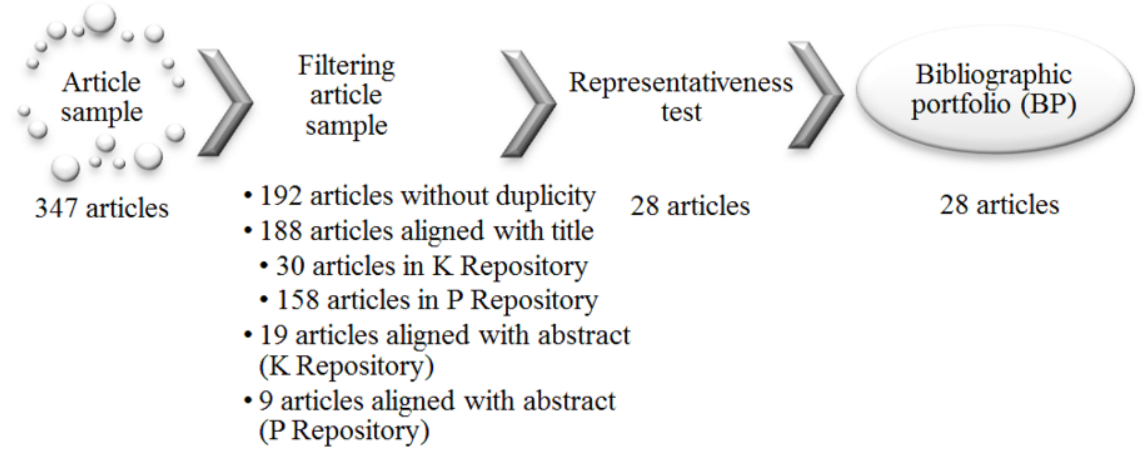

Figure 1. Bibliographic portfolio selection stage.

\subsection{Bibliometric Analysis}

In order to acquire the main characteristics of BP, a statistical analysis was performed on the set of articles that comprises the BP. The results of the bibliometric analysis are as follows [14-18]: 
Scientific certification. First of all, it is noteworthy that the portfolio is scientifically recognized. According to journal's relevance estimation, $80 \%$ of BP is constituted by the $20 \%$ most cited articles in the sample. The most cited article in the BP was entitled "Quantitative tools for cultivating symbiosis in industrial parks", by C. A. Kastner, R. Lau and M. Kraft, which was cited 45 times by other authors.

Author's relevance. The porftolio was written by 76 authors. The main authors in terms of research contribution were: L. Fraccascia, G. Mantese and D. Amaral, which contributed with 3 articles each, and I. Giannoccaro, M. Demartini, F. Bertani, D. Yazan and F. Tonelli, which written 2 articles each. About $88 \%$ of the BP was composed of authors who had published only once.

Most frequently used keywords. Regarding the keyword analysis, the total amount found in BP was 135 keywords. Around $43 \%$ of them appeared more than once in the BP articles. Among these, the most relevant keyword found was "industrial symbiosis", with 11 exposures. The second most used word was "agent-based modeling", being 7 times used. The keyword "industrial ecology" was the third most significant (5 times), followed by "system dynamics" (5 times), "simulation" (4 times), and "complexity", "eco industrial park", "industrial symbiosis network" and "performace indicators" (3 times each). The keywords found are aligned with the research axes defined at the beginning of this study.

Journal's relevance and impact factor analysis. The impact factor analysis was based on the Journal Impact Factor from Journal Citation Report (JCR). For analysis purposes, the last JCR year available and selected was 2017. According to this analysis, BP consists of 16 journals. 5 journals appeared most frequently in the portfolio. Sustainability was the most recurrent journal, with 5 publications and impact factor of 2.075. Moreover, 4 articles were published by Journal of Cleaner Production, which had the major impact factor (5.651), and 4 others by Journal of Industrial Ecology (4.356). Resource, Conservation and Recycling published 2 articles and had the second highest impact factor (5.120). It is also worth noting the Journal of Industrial Ecology that published 4 articles and had an indicator of 4.356. Studies in Computational Intelligence published 2 articles, but the impact factor analysis was not exposed due to lack of information. The other journals published only one article. Thereby, the portfolio journals are recognized in the industrial sustainability area.

Research theme evolution. The number of articles published on the research theme more than tripled from 2014 to 2017. In 2014, only 3 articles were written. On the other hand, 10 papers were published about the theme in 2017. This number decrease to 7 articles in 2018 . As the 2019 articles are in a process yet, there is only one article published this year. In summary, it's possible to conclude that the research theme is still a study in progress.

\subsection{Systemic Analysis}

In order to perform this analysis, the following criteria were determined: (i) type of article, (ii) proposal by the authors, (iii) methodology, (iv) main modeling features, (v) results, and (vi) opportunities and future works. The information regarding each criterion was extracted through a close reading of full portfolio papers. The main points discussed in the literature were condensed, according to the number of times addressed by the portfolio authors. Therefore, the components found can be seen, as follows: 
Complexity of industrial symbiosis network (ISN) - most of the articles consider that industrial symbiosis networks are complex [11, 12, 20-26]. The structure of this complex system is sophisticated and contains a large number of interacting components and the frequent interaction process between diverse relationships $[11,20,21]$. The design and management of ISNs must consider various issues such as the behavior over time of this industrial multi-agent system as well as mechanisms to monitor the commitment of involved industries to organizational objectives of the industrial symbiosis network [12]. Forming an ISN requires extensive knowledge from social, organizational, environmental spheres [23]. According to characteristics as uncertainty, emergence, or adaptability amongst others, an eco-industrial park (EIP) is considered a complex adaptive system (CAS). The traditional analytical method, such as numerical methods or other formula and semi-formula approaches, is difficult to study industrial symbiosis [11]. Thus, the system can be understood through modeling [22]. Despite the complexity, numerous ongoing efforts highlighted the need to develop industrial models by the scope of the industrial ecology [26]. The main approaches available that encompass these characteristics are agent-based modeling (ABM) and system dynamics (SD) [23, 24].

Evolutionary nature, dynamic and changing environment - approaching evolution and dynamic face on the changes within the industrial symbiosis environment is a great challenge. The evolutionary nature of models within a changing sociotechnical environment is a central aspect to sustain useful models in industrial ecology. Regarding these aspects, a multimodel ecology perspective is presented [26]. The interesting relationship of member enterprises in the ecological industry chain is a dynamic and repeated game process. [27]. The application of industrial symbiosis indicators to monitor evolution could further contribute to the system understanding [29]. In this sense, another opportunity identified is the lack of indicators which can predict the most critical characteristics for the system evolution. Thereby, the model could cooperate with decision-making based on evolutionary features [25]. Many studies mention evolution, dynamic and changes in the environment as an opportunity for a future approach. Some authors did not consider the dynamic introduction (or closure) of plants that can strongly shift the synergies created $[6,30]$.

Emergence and stability - few studies have investigated strategies and mechanisms to foster the emergence of stable ISNs. The adoption of contractual mechanisms ruling the symbiotic relationships between firms is an effective way to reach this emergence scenario. Thus, the importance of trust-based relationships is highlighted [31]. In further research, these authors developed a model to explores the efficacy of two specific policies (landfill tax and economic subsidy for IS exchanges) in supporting the emergence of self-organized ISNs. The simulation analysis confirmed that the policy measures have a positive effect on the emergence, both singularly and simultaneously implemented [32]. Different economic conditions, as well as structural settings in a later stage, can influence the efficiency and stability of ISNs over time. In this way, the emergence and development of IS is a process where the knowledge, attitude, and implementation of synergies are gradually adopted by firms [30].

Vulnerability and interdependencies - the interdependence of agents and the vulnerability of an industrial symbiosis system are important features to consider. According to [20], the creation of exchanges in ISN may create vulnerabilities. 
The authors mention a solution to structure favorable interactions between the occupants of the park and improve the understanding of vulnerabilities, through social network theory and technical elements. An interdependent network model preserving the heterogeneity of exchange content and the diversity of symbiosis relationships is proposed in [21]. The main goal is to advance the understanding of the interdependence and resilience of ISNs. The results of this study imply that ISNs may be highly vulnerable when disruption happens, especially in disruptions of structurally significant components, cascading effects, and interdependency between different IS systems. Managers from companies and governments should understand these factors and take effective corresponding actions to increase adaptability and enhance ISN resilience. A case study in the North-East of England reveals interesting in the emerging interdependencies, in particular in the sequence of the earlier waste policy and the later renewable energy policy. [33].

Material exchange and infrastructure sharing - according to some authors, there are two kinds of industrial symbiosis network: (i) that promotes an exchange of materials, and (ii) that promotes sharing of infrastructure [20, 21]. The flows of materials and energy represent the essential attribute of an industrial process, and the economic benefit is the basic target of an industrial enterprise [22]. Case studies suggest that material by-product exchanges may be a better starting point for existing industrial parks. This strategy may have less impact on infrastructure [20] and consequently fewer costs involved. Therefore, an important step toward a complete industrial symbiosis network is the development of models focused on the exchange of materials.

Methods addressing the differences between IS creation and adaptation - creating a new eco-industrial park is different from adapting an existing park. However, the same methods can be used for both situations, making alterations to existing structures has a different set of issues than new construction. A hybrid modeling approach enables the analysis and redesigning of industrial areas based on sustainable strategy with industrial symbiosis [13]. Although the IS development requires the application of analytic methodology and modeling tools to support and facilitate the process [30], there is a lack of methods that address the differences involving the creation and adaption of industrial symbiosis.

Social network theory, game theory and social attributes - few authors focus on social attributes to emphasize this critical feature of industrial symbiosis relationships. Social network theory develop favourable interaction structures between park occupants and may produce significant insights. The application of this theory combined with more technical elements can improve the understanding of vulnerabilities and other risk elements generated by interdependencies [20]. An introduction into the social networks modeling, including a dynamic variable resulting from social interactions and evolution of firms, is addressed by [31]. The design and simulation of some experiments to study the influence of the social structure (i.e., types of social network) and dynamics (i.e., creation of new social contacts between plants) reveal that both factors have an influence on synergy creation [6]. Some authors proposed the formalization of cooperative relations through game theory $[20,25]$. According to [25], this theory favors the consideration of multiple strategies in the decision-making process related to the preferences and individual objectives of each agent. Another study that raises the social relation question has created a model combining multi-agent based 
simulation (MABS) techniques with a social survey questionnaire to simulate the behavior change of the agents under different policy scenarios [11].

Information sharing, and model reuse and integration - information is the crucial condition for developing IS, and the lack hampers the exchange of resources between companies. One opportunity described is to explore the use of online platforms in IS identification to facilitate IS, the description of sensitive or nonsensitive information and the human factor in information sharing. Online platforms increase the economic and environmental performance of ISNs. So that, future directions for the interdisciplinary research on IS, combining operations management with information science research, are indicated [34]. A multimodel ecology perspective affirms that is not just about integrating computer software, but also about furthering the coevolution of our mental models and our computer models. Thus, important drivers and barriers of model reuse and integration were identified [26].

\section{Paradigms to industrial symbiosis modeling and simulating}

Through the systemic review, it was possible to identify that the industrial symbiosis is considered a complex adaptive system characterized by uncertainty, emergence, or adaptability, amongst others. The main approaches available to modeling and simulating this type of system are ABM and SD [24, 25]. Therefore, the key features about these approaches, found in the portfolio articles, were compiled. The main objective is to explore and provide information for the decision on which paradigm to use in the future IS model.

The agent-based modeling (ABM) approach is inductive or bottom-up [25]. ABM appears addressing issues related to cultivating cooperation or overcoming noncooperation. The most attractive feature is the ability to propose "if-then" situations, through behavioral rules or even more complicated learning algorithms. ABM allows model a system with a variety of agents or agent-types which have different goals, responses, autonomous entities and characterized by certain attributes [20, 25, 35, 36]. The overall system behavior emerges during the inference process from the interactions of the agents. This approach is suitable for modeling those systems that operate as an integrated service [25]. Agent-based simulation is an appropriate methodology to study CASs [31]. It is generally acknowledged that ABMS is the most significant and prospective technique for exploring dependencies among stakeholders involved in the complex system [11]. Some guidelines to cultivate a multimodel ecologies perspective report that an $\mathrm{ABM}$ requires to be documented and developed using documentation standards (e.g., ODD protocol) [26].

Agent-based simulation models of IS will eventually be able to support, in the context of industrial parks for which data is available, the identification of actions that are more likely to promote the creation of industrial synergies. Another theoretical benefit of agent-based models of IS dynamics is their ability to model and anticipate the technical impacts (e.g., technology investment, material flows, industrial synergy creation) of social actions in industrial parks, including eventually third-party facilitation and social networking [6]. Hence, the ABM serves also as a decisionsupport tool for companies to evaluate an existing IS relationship, to interrupt an existing IS and seek for a new partner and to create a new IS-based business [34]. The ABM approach provides a practical tool for addressing real-world problems with 
computational simulation experiments [30]. Agents have specialized knowledge for decision-making that they perform themselves. ABM is suited to types of problems in which equations cannot be formulated by a top-down approach. Although ABM can model a product as an entity at the usage stage, it cannot handle resource circulation such as parts reuse. Because the ABM approach cannot incorporate time delays, it does not track usage history of parts related to individual product life cycle systems [35].

The system dynamics (SD) approach is deductive or top-down [25]. The causal structure of the system dynamics considers feedback loops, time delays, flow diagrams, and stock accumulation. SD model includes the connections and interactions among individual elements for simulating the behavior of the entire system [35]. The endogenous system properties are represented as observables or level variables in SD models, which express the state of the system. The relationships amongst variables are nonlinear and are represented by feedback structures with time or space delays [25]. SD is a methodology used to model and simulate the complex system [11]. The SD method, which serves as a modeling and simulation tool specifically designed for long-term, dynamic problems, helps us visualize the effects of different strategies through simulation [37].

Furthermore, a hybrid system of ABM and SD has been proposed in order to address the unique characteristics of the IS problem $[9,13]$. As the ABM method is more recent, the SD method is more mature. The two paradigms can be applied in modeling and simulating of industrial symbiosis systems. The choice should be made based on the objectives of the system to be developed [25].

\section{Conclusion and Future Research}

The present article followed a methodological procedure called ProKnow-C to develop a bibliometric and systemic analysis of systems modeling and industrial symbiosis. The aim was to identify the current state of the literature, the main points discussed and opportunities found about the research theme.

Through the bibliometric analysis, from the initial sample of 347 articles selected in the databases, only 28 articles composed the bibliographic portfolio, representing the research theme. The results of the bibliometric analysis presented the statistical analysis of the portfolio articles in terms of scientific certification, author's relevance, most frequently used keywords, journal's relevance, and impact factor analysis, and research theme evolution.

During the systemic analysis stage, the 28 selected articles were thoroughly read. After that, the main points discussed and opportunities found were related to: complexity of industrial symbiosis networks; evolutionary nature, dynamic, changing environment; emergence and stability; vulnerability and interdependencies; material exchange and infrastructure sharing; methods addressing the differences between IS creation and adaption; social network theory, game theory and social attributes; and information sharing, and reuse and integrated models.

The main paradigms available to address the complexity of industrial symbiosis modeling and simulating are ABM and SD. The choice between one or other should be based on the features and objectives of the system to be modeled.

The bibliometric and systemic analysis, as well as the discussion about the approaches to IS modeling and simulating point the direction towards the new model 
construction. The bibliometric analysis presented the research theme relevance through statistical analysis. The systemic review identified the main features for the IS system modeling. Furthermore, this stage supports the prediction of how to handle with these features in the new model. As the future IS model intends to evaluate the material flow dynamic and address the main features of IS network, according to their attributes and behaviors, a hybrid approach model is assumed to be the path to this representation.

This research carried out a vertical analysis on the subject field, which in previous paper had already been addressed more broadly, through a horizontal review about material flow mapping and industrial ecosystems [38]. Although the whole Proknow-C process consumes quite a time, the procedure is still proving to be an efficient tool for the structured literature review. Due to the lack of details about the criteria for systemic analysis, it is worth noting that difficulties have arisen. Since the methodological process is iterative, a recommendation is to redo the steps with the new keywords collected through this study.

This paper is a preliminary study and intends to assist the research theme as a knowledge base. A future research plan is the development of the new IS model, focus on material exchange, which supports the decision-making process during the creation of symbiotic links.

\section{References}

[1] M. Despeisse, P. D. Ball, S. Evans and A. Levers, Industrial ecology at factory level-a conceptual model, Journal of Cleaner Production, 2012, Vol. 31, pp. 30-39.

[2] P. Deutz, Producer responsibility in a sustainable development context: ecological modernisation or industrial ecology?, The Geographical Journal, 2009, Vol. 175, No. 4, pp. 274-285.

[3] M. R. Chertow, Industrial symbiosis: literature and taxonomy, Annual review of energy and the environment, 2000, Vol. 25, No. 1, pp. 313-337.

[4] R. White, Preface. The Greening of Industrial Ecosystems, Edited by B. Allenby and D. Richards, National Academy Press, Washington, D.C., 1994.

[5] M. R. Chertow and J. Park, Reusing Nonhazardous Industrial Waste Across Business Clusters, In: T. M. Letcher and D. A. Vallero, Waste: A handbook for management, p. 197, 2011.

[6] M. R. Ghali, J. M. Frayret and C. Ahabchane, Agent-based model of self-organized industrial symbiosis, Journal of Cleaner Production, 2017, Vol. 161, pp. 452-465.

[7] M. R. Chertow, Uncovering industrial symbiosis, Journal of Industrial Ecology, 2007, Vol. 11, No. 1, pp. 11-30.

[8] R.V. Berkel, T. Fujita, S. Hashimoto and Y. Genga, Industrial and urban symbiosis in Japan: Analysis of the Eco-Town program 1997-2006, Journal of Environmental Manag., 2008, Vol. 90, pp. 1544-1556.

[9] M. Demartini, F. Tonelli and F. Bertani, Approaching industrial symbiosis through agent-based modeling and system dynamics, in Studies in Computational Intelligence, T. Borangiu, D. Trentesaux, A. Thomas, O. Cardin (eds) Service Orientation in Holonic and Multi-Agent Manufacturing, 2018, Vol. 762, pp. 171-185.

[10] E. Romero and M. C. Ruiz, Framework for applying a complex adaptive system approach to model the operation of eco-industrial parks, Journal of Industrial Ecology, 2013, Vol. 17, No. 5, pp. 731-741.

[11] X. Meng, Z. Wen and Y. Qian, Multi-agent based simulation for household solid waste recycling behavior, Resources, Conservation and Recycling, 2018, Vol. 128, pp. 535-545.

[12] V. Yazdanpanah, D. M. Yazan and W. H. M. Zijm, Normative industrial symbiotic networks: a position paper, Multi-Agent Systems and Agreement Technologies, 2016, pp. 314-321.

[13] M. Demartini, F. Bertani and F. Tonelli, AB-SD Hybrid Modelling Approach: A Framework for Evaluating Industrial Sustainability Scenarios, in Studies in Computational Intelligence, T. Borangiu, D. Trentesaux, A. Thomas, O. Cardin (eds.) Service Orientation in Holonic and Multi-Agent Manufacturing, 2019, Vol. 803, pp. 222-232.

[14] L. Ensslin, S.R. Ensslin and H.M. Pinto, Processo de investigação e análise bibliométrico: avaliação da qualidade dos serviços bancários, Revista de administração contemporânea, 2013, Vol.17, No.3, pp. 325-349. 
[15] J.E. Tasca, L. Ensslin, S.R. Ensslin and M.B.M. Alves, An approach for selecting a theoretical framework for the evaluation of training programs, Journal of European Industrial Training, 2010, Vol. 34, No. 7, pp. 631-655.

[16] L.C. Chaves, L. Ensslin, S.R. Ensslin, S.M.I Valmorbida, F.S da Rosa, Sistemas de apoio à decisão: mapeamento e análise de conteúdo, Revista Eletrônica de Ciência Administrativa, 2013, Vol. 12, No. 1, pp. 6-22.

[17] L. Ensslin, S.R. Ensslin, R.T.O. Lacerda and J.E. Tasca, ProKnow-C, Knowledge Development Process- Constructivist. Processo técnico com patente de registro pendente junto ao INPI, Brasil, 2010.

[18] J.S. Dienstmann, R.T.O Lacerda, L. Ensslin, S.R. Ensslin, Gestão da Inovação e Avaliação de Desempenho: processo estruturado de revisão da literatura, Revista Científica Eletrônica de Engenharia de Produção, Florianópolis, vol. 14, no. 1, pp. 2-30, jan./mar., 2014.

[19] L. Diez, P. Marange and E. Levrat, Regeneration Management Tool for Industrial Ecosystem, IFACPapersOnLine, 2017, Vol. 50, No. 1, pp. 12950-12955.

[20] C. A. Kastner, R. Lau and M. Kraft, Quantitative tools for cultivating symbiosis in industrial parks; a literature review, Applied Energy, 2015, Vol. 155, pp. 599-612.

[21] Y. Li and L. Shi, The resilience of interdependent industrial symbiosis networks: a case of Yixing economic and technological development zone, Journal of Industrial Ecology, 2015, Vol. 19, No. 2, pp. 264-273.

[22] G. Wang, X. Feng and C. Hoong, Symbiosis analysis on industrial ecological system. Chinese Journal of Chemical Engineering, 2014, Vol. 22, No. 6, pp. 690-698.

[23] B. Mileva-Boshkoska, B. Rončević and E. D. Uršič, Modeling and evaluation of the possibilities of forming a regional industrial symbiosis networks, Social Sciences, 2018, Vol. 7, No. 1, p. 13.

[24] E. Romero and M. C. Ruiz, Framework for applying a complex adaptive system approach to model the operation of eco-industrial parks. Journal of Industrial Ecology, 2013, Vol. 17, n. 5, pp. 731-741.

[25] E. Romero and M. C. Ruiz, Proposal of an agent-based analytical model to convert industrial areas in industrial eco-systems, Science of the Total Environment, 2014, Vol. 468, pp. 394-405.

[26] L. A. Bollinger, I. Nikolic, C. B. Davis, and G. P. J. Dijkema, Multimodel Ecologies Cultivating Model Ecosystems in Industrial Ecology, Journal of Industrial Ecology, 2015, Vol. 19, No. 2, pp. 252-263.

[27] I. H. Chen, An evolutionary game study of an ecological industry chain based on multi-agent simulation; A case study of the Poyang Lake Eco-Economic zone, Sustainability, 2017, Vol. 9, No. 7, p. 1165.

[28] G. C. Mantese and D. C. Amaral, Comparison of industrial symbiosis indicators through agent-based modeling, Journal of Cleaner Production, 2017, Vol. 140, pp. 1652-1671.

[29] G. C. Mantese and D. C. Amaral Agent-based simulation to evaluate and categorize industrial symbiosis indicators. Journal of Cleaner Production, 2018, Vol. 186, pp. 450-464.

[30] K. Zheng and S. Jia, Promoting the Opportunity Identification of Industrial Symbiosis; Agent-Based Modeling Inspired by Innovation Diffusion Theory, Sustainability, 2017, Vol. 9, No. 5, p. 765.

[31] V. Albino, L. Fraccascia and I. Giannoccaro, Exploring the role of contracts to support the emergence of self-organized industrial symbiosis networks: an agent-based simulation study, Journal of Cleaner Production, 2016, Vol. 112, pp. 4353-4366.

[32] L. Fraccascia,I. Giannoccaro and V. Albino, Efficacy of landfill tax and subsidy policies for the emergence of industrial symbiosis networks: an agent-based simulation study. Sustainability, 2017, Vol. 9 , No. 4 , p. 521.

[33] F Schiller, A. Skeldon, T. Balke, M. Grant, A. S. Penn, L. Basson, P; Jensen, N. Gilbert, O. D. Kalkan, A . Woodward, Defining relevance and finding rules: an agent-based model of biomass use in the Humber area. In: Advances in Social Simulation. Springer, Berlin, Heidelberg, 2014, pp. 373-384.

[34] L. Fraccascia and D. M. Yazan, The role of online information-sharing platforms on the performance of industrial symbiosis networks, Resources, Conservation and Recycling, 2018, Vol. 136, pp. 473-485.

[35] H. Kobayashi, T. Matsumoto and S. Fukushige, A simulation methodology for a system of product life cycle systems, Advanced Engineering Informatics, 2018, Vol. 36, pp. 101-111.

[36] H. Chandra-Putra, J. Chen and C. J. Andrews, Eco-evolutionary pathways toward industrial cities, Journal of Industrial Ecology, 2015, Vol. 19, No. 2, pp. 274-284.

[37] H. Cui, C. Liu, R. Cote and W. Liu, Understanding the Evolution of Industrial Symbiosis with a System Dynamics Model; A Case Study of Hai Hua Industrial Symbiosis, China, Sustainability, 2018, Vol. 10, No. 11, p. 3873.

[38] G. B. Guedes, L. B. Z. Paganin and M. Borsato, Bibliometric and Systemic Analysis on Material Flow Mapping and Industrial Ecosystems, Journal of Industrial Integration and Management, 2018, Vol. 03, No. 4, pp. 1-19. 